\title{
High-density cultivation of microalgae continuously fed with unfiltered water from a recirculating aquaculture system
}

Sophia Egloff, Fridolin Tschudi, Zala Schmautz, Dominik Refardt

Zurich University of Applied Sciences, Institute of Natural Resource Sciences, Campus Grüental, CH-8820 Wädenswil, Switzerland

\begin{abstract}
Water from recirculating aquaculture systems (RAS) has been shown to be a suitable growth medium for microalgae and their cultivation can, therefore, be used to reduce RAS emissions. However, while efficient wastewater treatment is possible, the nutrient content of RAS water limits attainable microalgae biomass densities to 1-2 $\mathrm{g} \mathrm{l}^{-1}$ at best, which requires frequent harvesting of microalgae. We have taken advantage of the constant evaporation of water from an open thinlayer photobioreactor (200 l volume, $18 \mathrm{~m}^{2}$ illuminated surface, artificial supply of $\mathrm{CO}_{2}$ ) to continuously add water from RAS to a microalgae culture and thereby provide nutrients for continued growth while evaporating all water. To test for a possible inhibitory effect of RAS water on microalgae growth, components of mineral medium were omitted stepwise in subsequent cultivations and replaced by RAS water as the only source of nutrients. This approach showed that microalgae can be grown successfully for up to three weeks in RAS water without additional nutrients and that high $\left(20 \mathrm{~g} \mathrm{l}^{-1}\right)$ biomass densities can be attained. While growth in wastewater did not reach productivities measured in mineral medium, analysis of growth data suggested that this reduction was not due to an inhibitory effect of the RAS water but due to an insufficient supply rate of nutrients, even though RAS water contained up to $158 \mathrm{mg} \mathrm{l}^{-1} \mathrm{NO}_{3}-\mathrm{N}$. It is, therefore, concluded that this method can be used to fully treat the wastewater discharge of a RAS. Furthermore, because both water evaporation from and microalgae growth in the photobioreactor correlated positively with each other due to their shared dependency on solar radiation, supply of nutrients continuously adjusts to changes in demand. It is estimated that the area of a photobioreactor required to treat all emissions of a RAS requires approximately 6.5 times the area of the latter.
\end{abstract}

\section{Introduction}

Aquaculture is a growing industry. While fishery production by capture has stabilized, aquaculture has experienced steady growth for the last two decades and is becoming the major source for human fish consumption [1]. This development places a heavy burden on the environment as it causes an increase in both feed demand [2] and wastewater discharge [3]. Solutions must be brought forward to make aquaculture more sustainable.

In recirculating aquaculture systems (RAS), the process water is recycled within the system through mechanical and biological filters, which reduces the demand of fresh water to less than $10 \%$ of that of conventional aquacultures [4]. Thus, RAS technology not only decreases wastewater discharge, it also increases the concentrations of nitrogen and phosphorous in the circulating water to levels that can support the production of plants [5]. This allows co-cultivation technologies 
such as aquaponics, where nutrients in the wastewater originally introduced with fish feed serve as fertilizer for the production of vegetables [6].

Here, we investigated the use of RAS water to cultivate microalgae, a promising renewable resource that is commercially used in a number of applications [7]. Microalgae cultivation lends itself to a coupling with aquaculture [8] because microalgae are the basis of the natural food chain in aquatic ecosystems and, thus, are an important food source to rear larvae of many fish species [9]. Furthermore, microalgal protein and lipids are candidates for the partial substitution of fish meal and fish oil in feed production [10]. However, the production of such lowcost commodities is hindered by high production costs [11].

In order to make the production of microalgae more economical, a number of solutions have been proposed, among them the recycling of waste products from other processes such as flue gas or wastewater to supply carbon and other nutrients respectively to the microalgal culture [12,13]. Besides lowering production costs, such a strategy has the added benefit that the cultivation process becomes more sustainable [14].

Wastewater from aquaculture, and in particular water from RAS, lends itself to the cultivation of microalgae for several reasons: First, nutrient composition in aquaculture wastewater matches the demand of microalgae and batch growth experiments support this [15-17]. Second, RAS water has a low content of organic substances, which minimises the growth of contaminating bacteria in a microalgal culture. Third, unlike in many other types of waste water, where ammonium is the main nitrogen compound, RAS water contains nitrate, which is more stable and less toxic for microalgae [18].

If microalgae are to be used beyond a mere treatment of the wastewater itself, it is important to attain high biomass densities to facilitate downstream processing. The concentration of the limiting nutrient in the wastewater sets the upper limit for microalgal growth, which then can be estimated by applying the Redfield ratio. Assuming that nitrogen is the limiting nutrient and occurs at a concentration of approximately $100 \mathrm{mg} \mathrm{l}^{-1}$ in a RAS, microalgal biomass may reach a maximum concentration of $1-2 \mathrm{~g} \mathrm{dw} \mathrm{l}^{-1}$, after which nitrogen levels are depleted. This corresponds to published values [19-21].

Microalgal biomass densities of $30 \mathrm{~g} \mathrm{dw} \mathrm{l}^{-1}$ or higher are possible with phototrophic cultivation, if conditions are optimized and a non-limiting supply of nutrients is ensured [22,23]. Because nutrient concentrations in wastewater are typically low [12], its subsequent addition requires the removal of an equal amount of culture volume and, thus, prohibits attaining a dense culture of microalgae.

Here, we propose to overcome this limitation by feeding water from a RAS to an open thin-layer photobioreactor [24]. Due to its open design and high surfacearea-to-volume ratio, up to $50 \%$ of the culture volume (5-6 $\mathrm{l} \mathrm{m}^{-2}$ ) evaporate on a single day [24] and must be balanced by supplying additional water. By using RAS water to offset evaporation, nutrients are provided constantly and the cultivation becomes a fed-batch instead of a batch cultivation. In addition, because both evaporation and photosynthesis are correlated due to their dependency on incident sunlight, the delivery of nutrients scales with its demand. 
To test whether the continuous supply of RAS water allows a productivity that is equivalent to cultivation in an artificial medium and allows to yield biomass densities beyond 1-2 $\mathrm{g} \mathrm{dw} \mathrm{l}^{-1}$, experimental cultivations of Chlorella vulgaris and Tetradesmus obliquus (syn. Acutodesmus obliquus, Scenedesmus obliquus) were conducted in an open thin-layer photobioreactor (200 l culture volume). This was done in a series of cultivations where a mineral medium was replaced stepwise by unfiltered water taken directly from a RAS.

\section{Materials and methods}

\section{Cultivation of microalgae}

All cultivations were carried out in an open thin-layer photobioreactor [24, constructed by BCS Engineering s.a., Brno, Czech Republic], situated in a foliar greenhouse on the Grüental campus of the Zürich University of Applied Sciences in Wädenswil, Switzerland (47¹3'2.09" N, 840'53.58" E). The reactor consisted of an inclined culture surface made of glass sheets in a steel frame on which an algal suspension was circulated (Figure 1). At the lower end of the surface, the suspension was collected in a tank and then pumped up again with a centrifugal pump. The culture surface had an inclination of $1.7 \%$, a length of $18 \mathrm{~m}$, and a width of $1 \mathrm{~m}$. On the surface, the layer of algal suspension had thickness of 6-8 mm and a velocity of $0.5 \mathrm{~m} \mathrm{~s}^{-1}$. The thickness of the suspension layer was regulated by coupling an ultrasonic sensor to the pump via a proportional integral (PI) controller.

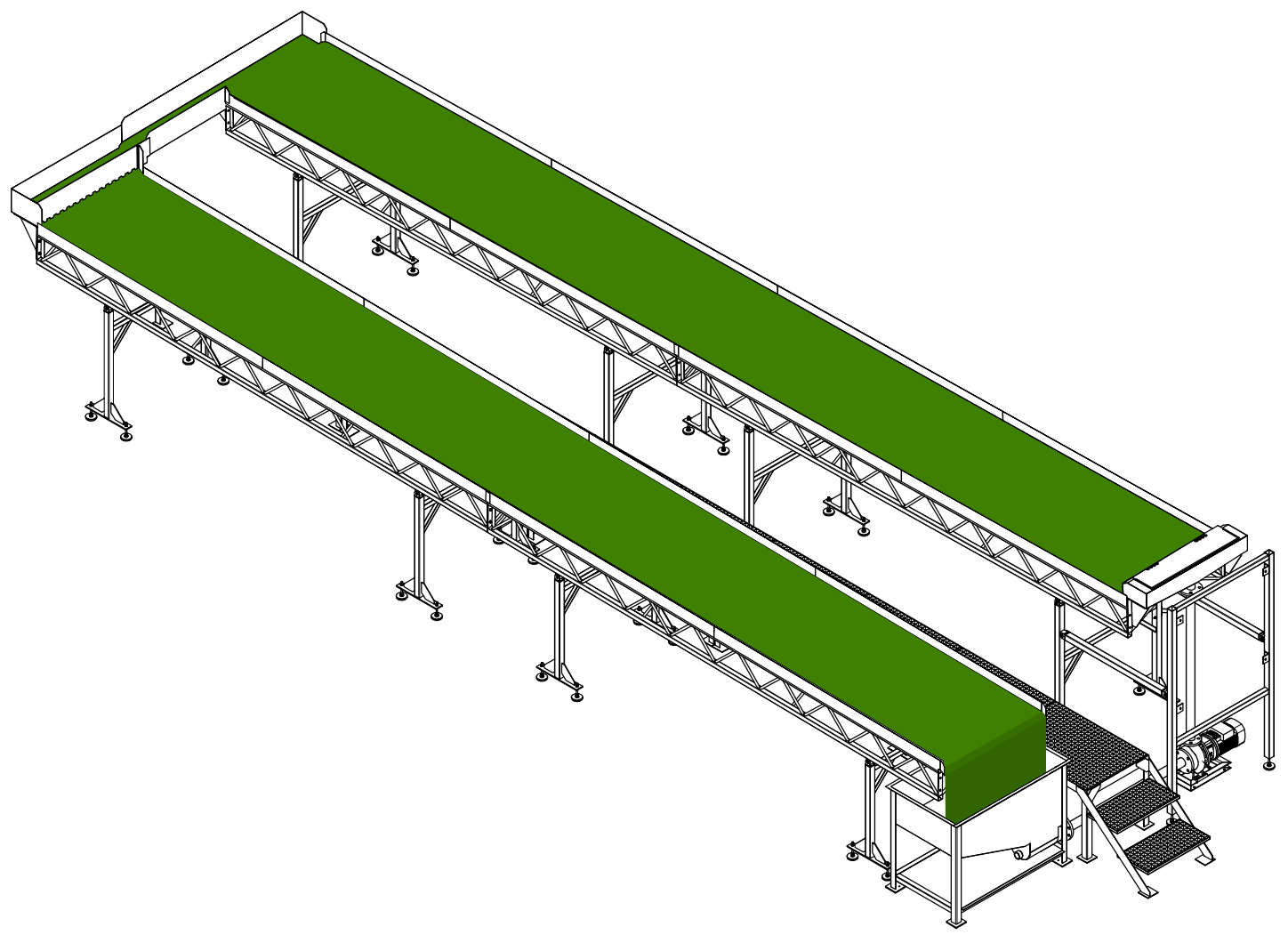

Figure 1: Drawing of the open thin-layer photobioreactor used in this study.

Chlorella vulgaris (strain CASSIE/CCAP 211-52) was used for all cultivations in 2014 (Table 1). Early in 2015, an undescribed Chlorella-specific infection prevented its subsequent use and a natural isolate of Tetradesmus obliquus was 
used instead. If not indicated otherwise, a mineral fertilizer [25] was added regularly, so that nutrients never became limiting. The fertilizer consisted of the macronutrients $\left(\mathrm{NH}_{2}\right)_{2} \mathrm{CO}(3.05 \mathrm{mM}), \mathrm{KH}_{2} \mathrm{PO}_{4}(0.29 \mathrm{mM}), \mathrm{MgSO}_{4}(0.14 \mathrm{mM})$, EDTA FeNa $(0.02 \mathrm{mM}), \mathrm{CaCl}_{2}(0.13 \mathrm{mM})$, and the micronutrients $\mathrm{H}_{3} \mathrm{BO}_{3}(2.78 \mu \mathrm{M}), \mathrm{CuSO}_{4}$ $(0.77 \mu \mathrm{M}), \mathrm{MnCl}_{2}(2.77 \mu \mathrm{M}), \mathrm{CoSO}_{4}(0.37 \mu \mathrm{M}), \mathrm{ZnSO}_{4}(1.55 \mu \mathrm{M}),\left(\mathrm{NH}_{4}\right)_{6} \mathrm{Mo}_{7} \mathrm{O}_{24}$ $(23.2 \mathrm{nM}),\left(\mathrm{NH}_{4}\right) \mathrm{VO}_{3}(20.0 \mathrm{nM})$. Molar concentrations given allow growth of $1 \mathrm{~g} \mathrm{l}^{-}$ ${ }^{1}$ microalgae biomass (dry weight) and the fertilizer was dosed accordingly. 
Table 1. List of all experimental cultivations that were performed to explore to what degree unfiltered water from a recirculating aquaculture system (RAS) can be used instead of artificial medium (mineral fertilizer, desalinated tap water) for the cultivation of microalgae (Chlorella vulgaris, Tetradesmus obliquus). Nitrate measurements were made for every batch of RAS water or twice a week when sourcing directly from the RAS. Daily evaporation and daily growth are estimated via linear regression (mean slope \pm SEM) from data shown in Figure 2 and S1.

\begin{tabular}{|c|c|c|c|c|c|c|}
\hline No. & Duration & Nutrient and water sources & Species & $\begin{array}{l}\mathrm{NO}_{3}-\mathrm{N} \text { concentration in } \\
\mathrm{RAS} \text { water in } \mathrm{mg} \mathrm{l}^{-1} \\
(\text { mean } \pm \mathrm{SD} \text { ) }\end{array}$ & $\begin{array}{l}\text { Evaporation in } 1 \mathrm{~m}^{-} \\
{ }^{2} \mathbf{d}^{-1}(\text { mean } \pm S E M)\end{array}$ & $\begin{array}{l}\text { Growth in } \mathrm{g} \mathrm{l}^{-1} \mathrm{~d}^{-1} \\
(\text { mean } \pm \text { SEM })\end{array}$ \\
\hline 1 & 14.05.-10.06.14 & $\begin{array}{l}\text { Mineral fertilizer, desalinated } \\
\text { tap water }\end{array}$ & Chlorella vulgaris & - & $4.01 \pm 0.02$ & $0.83 \pm 0.03$ \\
\hline 2 & 12.07.-22.07.14 & $\begin{array}{l}\text { Mineral fertilizer, desalinated } \\
\text { tap water }\end{array}$ & Chlorella vulgaris & - & $4.74 \pm 0.02$ & $1.86 \pm 0.10$ \\
\hline 3 & 22.07.-10.08.14 & $\begin{array}{l}\text { Mineral fertilizer, desalinated } \\
\text { tap water }\end{array}$ & Chlorella vulgaris & - & $3.04 \pm 0.02$ & $1.39 \pm 0.02$ \\
\hline 4 & 14.08.-02.09.14 & $\begin{array}{l}\text { Mineral fertilizer, desalinated } \\
\text { tap water }\end{array}$ & Chlorella vulgaris & - & not measured & $0.99 \pm 0.03$ \\
\hline 5 & 02.09.-07.10.14 & $\begin{array}{l}\text { Mineral fertilizer, unfiltered } \\
\text { RAS water }\end{array}$ & Chlorella vulgaris & not measured & $4.24 \pm 0.05$ & $0.82 \pm 0.03$ \\
\hline 6 & 19.06.-07.07.14 & $\begin{array}{l}\text { Mineral fertilizer without } \\
\text { nitrogen, unfiltered RAS water }\end{array}$ & Chlorella vulgaris & $67.0 \pm 5.7$ & $3.56 \pm 0.01$ & $0.37 \pm 0.03$ \\
\hline 7 & 22.07.-17.08.15 & $\begin{array}{l}\text { Microelements, unfiltered RAS } \\
\text { water }\end{array}$ & $\begin{array}{l}\text { Tetradesmus } \\
\text { obliquus }\end{array}$ & $139.6 \pm 5.3$ & $3.89 \pm 0.01$ & $0.83 \pm 0.03$ \\
\hline 8 & 18.08.-09.09.15 & Unfiltered RAS water & $\begin{array}{l}\text { Tetradesmus } \\
\text { obliquus }\end{array}$ & $148.6 \pm 5.0$ & $3.60 \pm 0.01$ & $0.80 \pm 0.06$ \\
\hline 9 & 09.09.-22.09.15 & Unfiltered RAS water & $\begin{array}{l}\text { Tetradesmus } \\
\text { obliquus }\end{array}$ & $157.7 \pm 3.1$ & $2.16 \pm 0.01$ & $0.61 \pm 0.05$ \\
\hline
\end{tabular}


During the day, food-grade $\mathrm{CO}_{2}$ was injected into the suction pipe of the suspension circulating pump. Dissolved $\mathrm{CO}_{2}$ was measured just before the point of injection by means of a Severinghaus electrode (InPro ${ }^{\circledR} 5000 \mathrm{i}$, Mettler Toledo, Greifensee, Switzerland), which then regulated the supply of $\mathrm{CO}_{2}$ via a PID controller. $\mathrm{CO}_{2}$ partial pressure in the algal suspension was kept at 10 mbar. At night, no $\mathrm{CO}_{2}$ was supplied. Switching between day and night modes was based on local sunrise and sunset times.

The $\mathrm{pH}$ of the algal suspension was recorded every minute with a $\mathrm{pH}$ electrode (InPro ${ }^{\circledR 3253 i}$, Mettler Toledo). The electrode was calibrated before every cultivation. The same sensor was used to measure temperature of the microalgal suspension.

Growth was monitored by daily dry weight measurements (HB43-S-Halogen Moisture Analyzer, Mettler Toledo) of the algal suspension.

Photosynthetically active photon flux density (PPFD; $\mu \mathrm{mol} \mathrm{m} \mathrm{m}^{-2} \mathrm{~s}^{-1}$ ) was measured with two sensors (SKL2620, Skye Instruments Ltd, Powys, UK) placed above and below the glass platform. The number of photons absorbed was calculated as the difference between the measurements of both sensors. PPFD was converted to photosynthetically active radiation (PAR, $\mathrm{W} \mathrm{m}^{-2}$ ) by multiplication with $2.02 \cdot 10^{-5} \mathrm{~mol}^{-1} \mathrm{~J}$ [23]. Data on global radiation $\left(\mathrm{W} \mathrm{m}^{-2}\right)$ outside of the greenhouse in which the photobioreactor was located were obtained from the Federal Office of Meteorology and Climatology (station Wädenswil, 10-minute averages). These data were used to estimate the loss of light inside the greenhouse. It was assumed that $45 \%$ of the energy of global radiation are within the PAR spectrum [26].

The volume of the circulating algal suspension was continuously monitored by means of a pressure sensor in the suspension tank. Total volume was $200 \mathrm{l}$ and water loss by evaporation was balanced whenever the volume fell below $195 \mathrm{l}$. A water meter at the inlet pipe measured the amount of added water and was used to estimate evaporation (readings were taken every minute). Depending on the experimental conditions, water was either partially desalted tap water (Ministil Clean HT, BWT, Austria) or unfiltered water from a RAS (see below).

Concentrations of nitrogen compounds (ammonium, nitrite, nitrate) in water samples were measured with photometric test kits (Hach-Lange, Rheineck, Switzerland) or ion-chromatography (930 Compact IC Flex, Metrohm, Zofingen, Switzerland).

\section{Recirculating aquaculture system}

RAS water was supplied from two different systems in 2014 and 2015. The RAS used in 2014 consisted of three interconnected circular fiber glass fish tanks with a total volume of $5 \mathrm{~m}^{3}$. Water from the tanks was drained through a central bottom-outlet to a 60- $\mu \mathrm{m}$ drum filter (Hydrotech HDF 501, Veolia, Saint-Maurice, France) into a moving-bed filter, enriched with pure oxygen, and returned to the tanks.

Tanks were stocked with 100-g Pike Perch (Sander lucioperca) to a stocking density of $20 \mathrm{~kg} \mathrm{~m}^{-3}$ and were fed with commercial fish feed (Aller Metabolica, Emsland Aller Aqua GmbH, Golssen, Germany). Daily feed amounted to $1.5 \%$ of the fish body weight $\left(1.53 \mathrm{~kg} \mathrm{~d}^{-1}\right)$. 
The RAS used in 2015 hat a total volume of $4 \mathrm{~m}^{3}$ and consisted of one rounded square fish tank with a volume of $2.9 \mathrm{~m}^{3}$. Water from the tank was drained through a central bottom outlet to a 60- $\mu \mathrm{m}$ drum filter (L500, Lavair AG Klimatechnik, Aach, Germany) into a moving bed biofilter enriched with pure oxygen and returned to the tank. Faeces and fish feed leftovers removed with the drum filter were collected in a radial flow settler and the supernatant was returned back. Settled sludge (7-10 l) was manually removed from the system three times per week.

The tank was stocked with 500-g Tilapia (Oreochromis niloticus) to a stocking density of $8.5 \mathrm{~kg} \mathrm{~m}^{-3}$. Fish were fed $2 \%$ of their body weight per day with commercial fish feed (Tilapia Vegi $4.5 \mathrm{~mm}$, Hokovit, Hofmann Nutrition AG, Bützberg, Switzerland).

\section{Experimental cultivations of microalgae}

To be able to assess whether the use of RAS water for microalgae cultivation has an influence on the growth performance, consecutive cultivations were carried out, where artificial medium was replaced stepwise with unfiltered water from the RAS (Table 1). This approach allows to test, and subsequently exclude, possible causes for a decrease in growth performance that may occur when artificial medium is replaced with RAS water, such as the effect of RAS water itself (cultivation no. 5), replacement of nitrogen (cultivation no. 6), replacement of micronutrients (no. 7) and complete replacement of artificial medium (no. 8 and 9).

Cultivations were seeded with 5-1 inocula grown in an incubator (Multitron Pro, Infors HT, Bottmingen, Switzerland) at $25{ }^{\circ} \mathrm{C}, 5 \% \mathrm{CO}_{2}, 150 \mathrm{rpm}$, constant illumination and mineral medium to a biomass density of $1 \mathrm{~g} \mathrm{l}^{-1}$.

RAS water was provided by two means. In 2014, unfiltered water from the RAS was taken directly out of the fish tank and kept in an intermediate bulk container (IBC) from where it was pumped into the culture as needed. To this end, a pump was submersed into the IBC and controlled via the water level indicator of the photobioreactor. The IBC was emptied, rinsed and refilled with water from the RAS every four days. In every batch, the nitrate concentration was measured. Together with the data on evaporation, these data were used to calculate the supply rate of nitrogen to the photobioreactor in 10-minute intervals. In 2015, the water was pumped directly from the fish tank into the culture as needed. Concentrations of ammonium, nitrite, and nitrate in the RAS water were measured twice per week.

Data on incident sunlight and nitrogen supply via the RAS water were used to predict how much biomass growth is to be expected in experiments no. 6-9 for every 10-minute interval of the experiment: First, data on incident sunlight and the photosynthetic efficiency estimated from experiments no. 1-4 were used to calculate the upper limit of biomass growth and, thus, the amount of nitrogen required. Second, the available nitrogen was calculated as the sum of the amount currently present in the culture medium and what was supplied additionally to offset evaporation loss. If the amount of available nitrogen was lower than the required amount, less biomass growth was predicted. The consumed nitrogen was 
then subtracted from the pool of available nitrogen before calculations were repeated for the next interval.

Duplicate biomass samples were taken at the end of cultivations 4-6 and subjected to CHN-analysis. Samples were dried at $105^{\circ} \mathrm{C}$ for $24 \mathrm{hrs}$ and grinded with a ball mill. $100 \mathrm{mg}$ of dried sample were combusted at $950{ }^{\circ} \mathrm{C}$ and analysed by means of infrared spectroscopy and thermal conductivity (TruSpec Macro Analyser, Leco Instruments Ltd, UK).

To obtain estimates of the relationship between incident light, culture temperature, and evaporation, data from all nine experiments were pooled. The relationship between incident light and biomass growth was explored with pooled data from cultivations 1-4, where growth was light-, and not nutrient-limited.

Data were analysed using R statistical software version 3.4.1 [27]. Productivities of all cultivations were compared with an ANCOVA (dependent variable: biomass density; explanatory variables: time (continuous), cultivation (9 levels)). Linear regressions were calculated between incident light, culture temperature, and evaporation respectively. The correlation between incident light and growth of microalgae was explored with a non-parametric test because outliers distorted the linear regression and rendered the estimated parameters useless. Data and $\mathrm{R}$ scripts are provided in the supplementary material.

\section{Results}

\section{Suitability of RAS water as growth medium}

Microalgae were grown successfully in all nine cultivations that were carried out (Figure 2). Cultivations lasted between ten and 35 days and final biomass densities (dry weight) between 8.6 and $29.7 \mathrm{~g} \mathrm{l}^{-1}$ were attained. Most importantly, cultivations where mineral fertilizer was replaced partially or fully with RAS water reached final densities up to $21.4 \mathrm{~g} \mathrm{l}^{-1}$ (with supplementation of microelements) and $18.7 \mathrm{~g} \mathrm{l}^{-1}$ (without supplementation of microelements), indicating that the continuous replacement of evaporated water with RAS water during microalgae cultivation is feasible and allows biomass densities to increase considerably when compared to cultivation in a single batch of wastewater. 

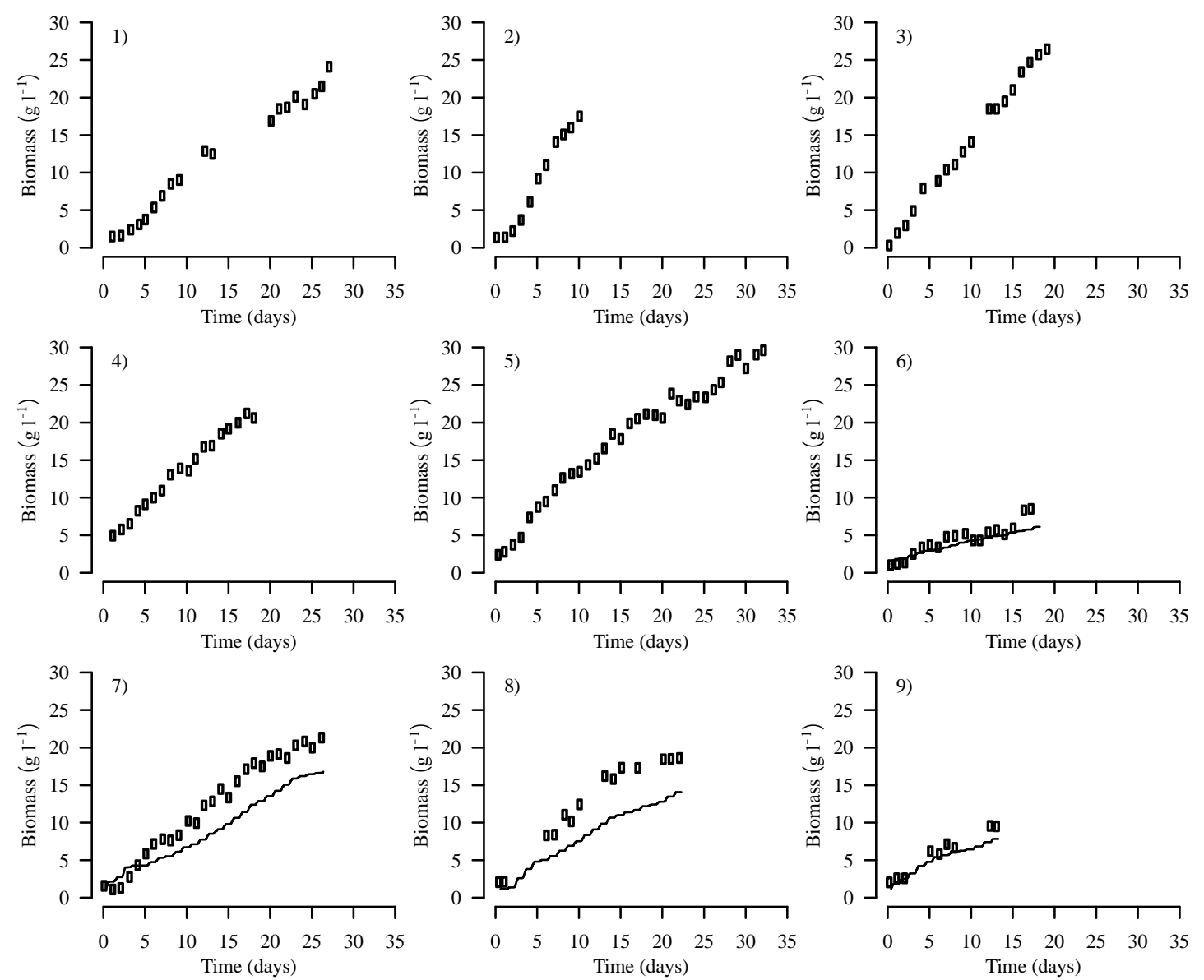

Figure 2: Growth of microalgae in nine separate cultivations as listed in Table 1. Solid curves in cultivations 6-9 are the projected growth based on incident light and nitrogen supplied with water from a recirculating aquaculture system.

By cultivating microalgae in RAS water with mineral fertilizer and by reducing the added components of the mineral fertilizer stepwise in subsequent cultivations, we aimed at detecting whether RAS water per se or its nutrient content had a discernible effect on microalgae growth (cultivations no. 5-9).

Productivity (slopes in Figure 2) varied among cultivations and caused a significant interaction between the factors time and cultivation in the linear model fitted to the growth data $\left(\mathrm{F}_{8,149}=44.7, p<0.001\right)$. However, these differences may not be caused by water quality but by seasonal variation (cultivations were carried out between April and October, Table 1).

Seasonal variability was excluded by estimating photosynthetic efficiency (PE) in every cultivation. PE is the proportion of absorbed solar energy (measured as PAR) that is stored as biochemical energy and, thus, corrects for differences in solar radiation between cultivations. Estimates of PE in cultivations 2-5, where mineral fertilizer was supplied, were $0.078,0.080,0.069$ and 0.069 respectively (sensor malfunction caused a data gap in cultivation 1). They represent a benchmark for growth that is not nutrient-limited. Estimates in cultivations 6-9, where nutrients were supplied partially or fully via RAS water, were $0.023,0.042$, 0.048 and 0.050 respectively, which is significantly lower $\left(\mathrm{t}_{6}=4.88, p=0.003\right)$. This indicates that growth in RAS water was reduced.

We deem an inhibitory effect of RAS water unlikely as an explanation for the reduced growth because cultivation 4 , which was carried out in RAS water but 
received mineral fertilizer, had both a high PE (0.069) and a high final biomass density (29.7 $\left.\mathrm{g} \mathrm{l}^{-1}\right)$. Instead, this suggests that an insufficient supply of nutrients reduced growth.

To test this, we used the available data on evaporation and nitrogen concentration in the RAS water (Table 1, Figure S1) and calculated the amount of nitrogen that was supplied to the cultivations via RAS water for every 10-min time step. Together with the data on solar irradiance during the same time, we predicted a growth trajectory based on the assumptions that PAR is converted to biomass with a PE of 0.0757 (average of cultivations 2-4) and that biomass contained $23 \mathrm{~kJ} \mathrm{~g}^{-1}$ (unpublished results) and $8.55 \% \mathrm{~N}$. The estimated growth trajectories fit the observed growth well (Figure 2). The estimated concentration of available nitrogen in the medium declined rapidly within the first days of cultivation and confirms that growth was nutrient-limited thereafter in all cultivations (Figure 3). Nitrogen limitation is further supported by the observation that $\mathrm{C} / \mathrm{N}$ ratios in the final biomass of cultivation 6 were markedly increased (11.19) compared to cultivations 4 (7.20) and 5 (6.55).
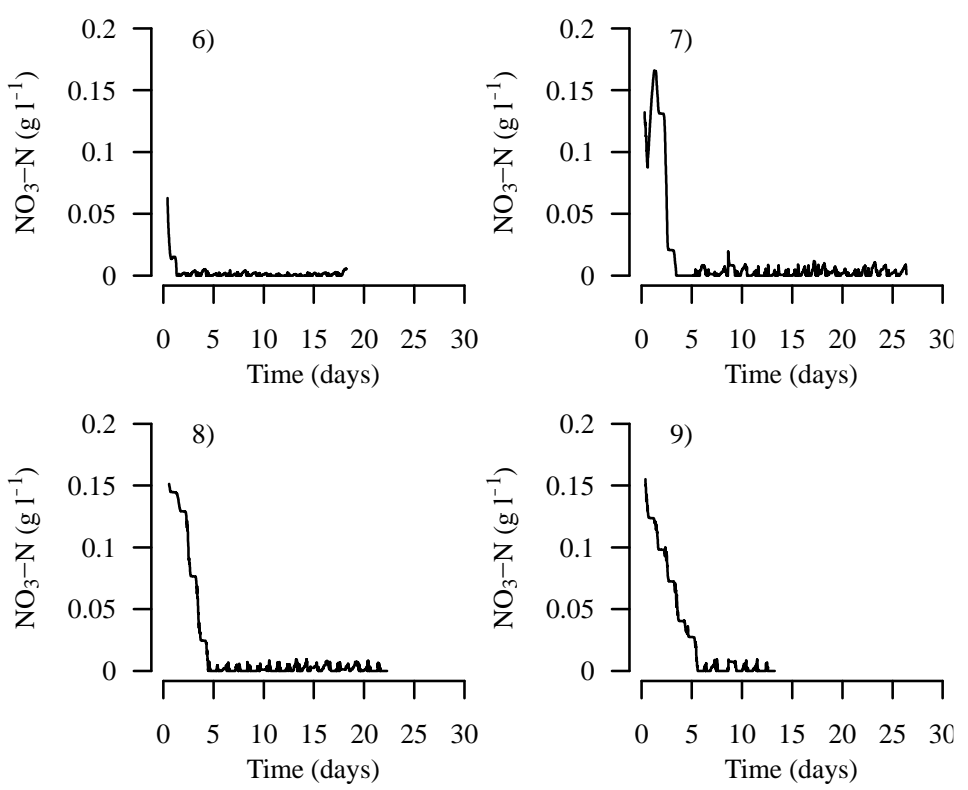

Figure 3: Estimated concentrations of available nitrate in cultivations 6-9 based on the amount of nitrate supplied via water from a recirculating aquaculture system and the projected amount that is consumed by microalgae based on the observed biomass increase.

Together, the available evidence indicates that diminished growth in RAS water is due to an insufficient supply of nutrients, possibly nitrogen, and not due to an inhibitory effect of the RAS water.

\section{Light-dependency of both algal growth and nutrient supply}

Across all nine cultivations that were carried out, the average daily energy input by radiation in the $400-700 \mathrm{~nm}$ spectrum was $1.17 \mathrm{kWh} \mathrm{m}^{-2}$ and the average daily evaporation was $3.49 \mathrm{l} \mathrm{m}^{-2}$.

As expected, incident sunlight determined the amount of water that had to be added to balance evaporation. Average daily culture temperature correlated with PAR (Figure 4A, $r^{2}=0.62, \mathrm{p}<0.001$ ) and hence evaporation also correlated with PAR (Figure 4B, Spearman's $\rho=0.87, \mathrm{p}<0.001$ ). In cultures $1-5$, where growth was not nutrient-limited, PAR correlated with biomass growth, which indicates 
that growth was limited by light (Figure 4C, Spearman's $\rho=0.48, p<0.001$ ). In cultures 6-9, where growth was nutrient-limited and nutrients were supplied partially or fully via RAS water, PAR also correlated with biomass growth (Figure $4 \mathrm{D}, r^{2}=0.09, \mathrm{p}=0.012$ ). This correlation is likely due to the dependency of nutrient supply on irradiance because the latter determines evaporation and, thus, the amount of RAS water delivered to the culture.

A)

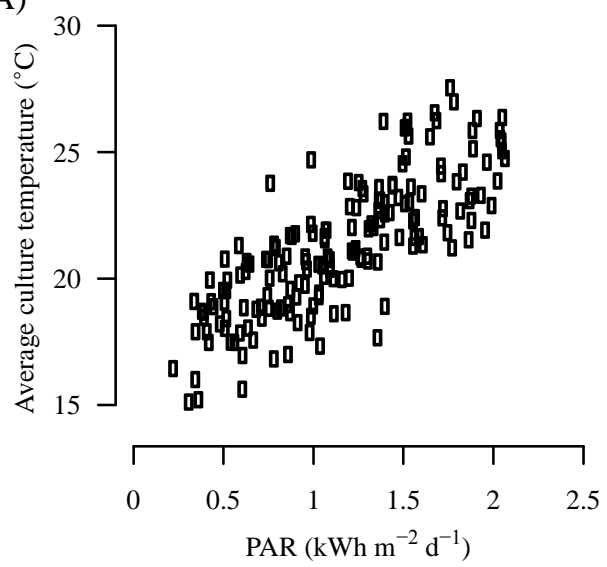

C)

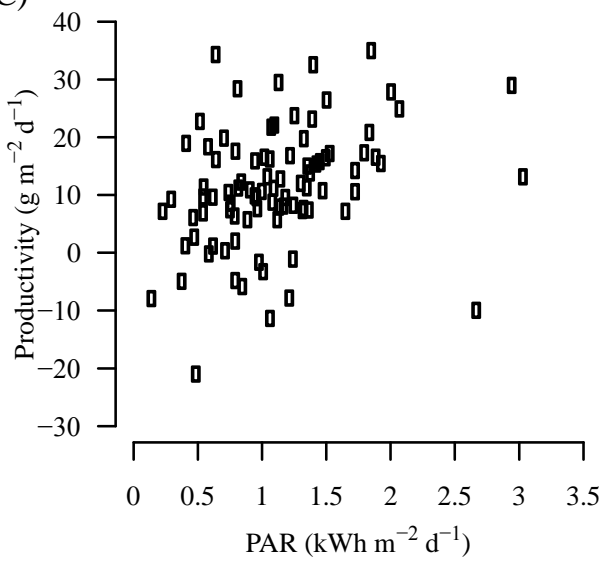

B)

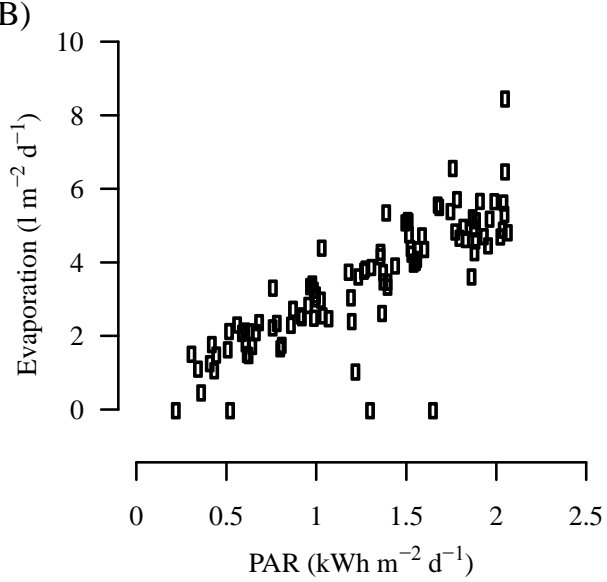

D)

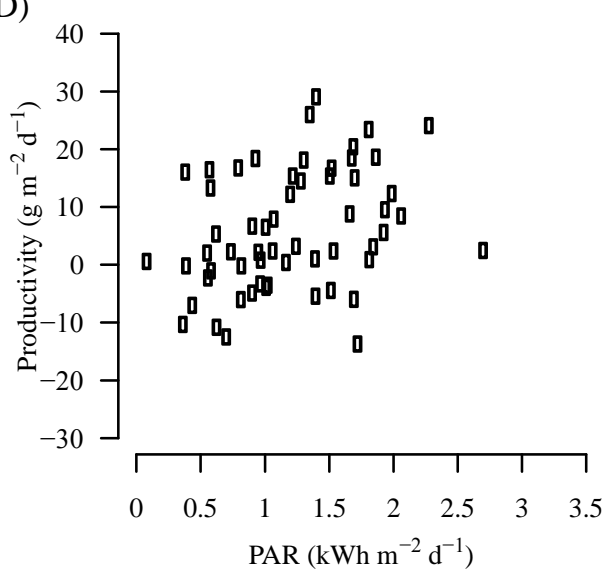

Figure 4: Irradiance (daily average photosynthetically active radiation (PAR) per $\mathrm{m}^{2}$ ) determines culture temperature (A) and thereby also evaporation in the same period (B). In cultures with non-limited nutrient supply, algal growth is directly limited by the available sunlight and hence the two variables correlate (C). In cultures where nutrients are supplied via water from a recirculating aquaculture system, growth is nutrientlimited but still correlates with irradiance because the supply of nutrients is driven by evaporation (D).

\section{Discussion}

We have tested whether microalgae can be cultivated in an open thin-layer photobioreactor, where evaporation is continuously balanced by adding water (and thereby nutrients) from a recirculating aquaculture system (RAS). Growth was limited by nutrient supply (possibly nitrogen), which implies that such a setup is capable of treating the full wastewater discharge of a RAS given that seasonal conditions are favourable for microalgae growth. A possible application of the setup presented here would be its integration into a multi-trophic system, where microalgae biomass is subsequently used as feed for other aquatic organisms $[8,28]$.

Our results indicate that unfiltered water from a RAS does not inhibit microalgae growth and sustains good productivities over extended periods of time (at least three weeks) without the need to intervene with the cultivation. This is an 
important finding because batch cultivations in process water may not detect issues that are caused by a slow build-up of toxins or missing trace nutrients, which were present in sufficient amounts at the start of the batch cultivation [29].

It is interesting to ask how the area of the photobioreactor compares to the amount of fish feed that eventually can be converted into microalgae biomass in order to obtain an estimate of the area required to treat wastewater from a RAS. Fish feed may contain 35\% protein, which, once fed to the fish, yields $0.092 \mathrm{~g} \mathrm{NH}_{4}$ $\mathrm{N}$ per $g$ protein and after nitrification an equal amount of $\mathrm{NO}_{3}-\mathrm{N}$ [4]. Hence, $1 \mathrm{~kg}$ of feed yields $32 \mathrm{~g}$ of nitrogen that can be converted to $508 \mathrm{~g}$ microalgae biomass (assuming a nitrogen content of 6.3\%). The average productivity of a thin-layer photobioreactor was estimated around $23.5 \mathrm{~g} \mathrm{dw} \mathrm{m}^{-2} \mathrm{~d}^{-1}$ [24], which would require $1 \mathrm{~m}^{2}$ to treat the emissions of $46 \mathrm{~g}$ of fish feed fed per day. This compares favourably to aquaponics, where hydroponically grown plants remove nutrients from the RAS water and it has been estimated that $1 \mathrm{~m}^{2}$ of plant growing area may take up the emissions of 15-42 $\mathrm{g}$ fish feed [30].

Equally, it is possible to roughly estimate how the area of the photobioreactor compares to the area of an aquaculture facility: We assume that $30 \%$ of the building are occupied by fish tanks that are stocked with $50 \mathrm{~kg}$ fish per $\mathrm{m}^{3}$. Fish may receive $2 \%$ feed per body weight and day. This amounts to $300 \mathrm{~g}$ feed per $\mathrm{m}^{2}$ and day for the whole building. Thus, the photobioreactor occupies 6.5 times the area of the aquaculture facility, if all emissions are to be taken up.

We are aware that the above projections depend strongly on the assumptions made and can easily be rendered more or less favourable. One limiting factor, however, is the relationship between the feeding rate/stocking density and the nitrate concentration in the RAS water. In order to operate the photobioreactor close to its maximum productivity, approximately $1.5 \mathrm{~g}$ nitrogen must be supplied per $\mathrm{m}^{2}$ per day. Given a maximum evaporation of 5-6 $\mathrm{l} \mathrm{m}^{-2} \mathrm{~d}^{-1}[24]$, this requires a concentration of up to $300 \mathrm{mg} \mathrm{l}^{-1} \mathrm{NO}_{3}-\mathrm{N}$, a concentration that may be tolerated by some fish, but certainly not all [31].

Average productivities in this study that were achieved under conditions where nutrients were supplied in non-limiting quantities (Figure 4C) were lower than published values [24]. This is due to the placement of the photobioreactor in a greenhouse, where irradiation was reduced (Figure 4). Likewise, evaporation was reduced (Figure 4B), possibly due to reduced air circulation and higher humidity. The estimated photosynthetic efficiencies, however, were comparable to published values [23] and indicate that the performance of the photobioreactor was good, given the circumstances.

The additional reduction in productivity that was observed when RAS water was used was due to an insufficient supply of nutrients (between 67 and $157 \mathrm{mg} \mathrm{l}^{-1}$ $\mathrm{NO}_{3}-\mathrm{N}$ ). This cannot be overcome by increasing the irradiation because growth and evaporation are coupled and will change concomitantly (Figure 4). Overcoming this limitation requires an increase in nutrient concentration in the RAS water or an increased mass flow to the photobioreactor, which requires an increased evaporation only. We project that concentrations up to $300 \mathrm{mg} \mathrm{l}^{-1} \mathrm{NO}_{3}$ $\mathrm{N}$ can be treated. 
Interestingly, despite feeding the water from our RAS to the photobioreactor without prior filtration, none of the cultivations showed a notable decline in productivity due to biological contaminants, such as parasites or predators. This is in contrast to our own unpublished results, where we observed that herbivorous protozoa in RAS water can have a severe impact on productivity when measured in batch cultures in the laboratory [32, unpublished results]. To our knowledge, most studies on cultivation of microalgae in aquaculture wastewater were either carried out under quasi sterile conditions $[19,21]$ or at a timescale not suitable to detect effects of herbivores [16].

A possible explanation for the apparent robustness of the cultivations lies in the more extreme environment that our photobioreactor presents compared to a raceway pond or benign laboratory conditions [33]: temperature fluctuates daily by more than $15^{\circ} \mathrm{C}$ (Figure S2), the addition of $\mathrm{CO}_{2}$ during the day causes rapid $\mathrm{pH}$ shifts (Figure S3), and the centrifugal pump is likely to exert considerable shear stress. Nevertheless, the occurrence of an infection that destroyed a complete culture grown in mineral medium during the same time period and in the same system suggests that chance may have played a role, as well, and points to the importance of acquiring more knowledge on the specific conditions that allow infections to invade a microalgae cultivation.

\section{References}

[1] OECD/FAO, OECD-FAO Agricultural Outlook 2013, OECD Publishing, Paris, 2013. https://doi.org/10.1787/agr_outlook-2013-en.

[2] A.G.J. Tacon, M.R. Hasan, M. Metian, Demand and supply of feed ingredients for farmed fish and crustaceans, FAO Fish. Aquac. Tech. Pap. 564 (2011).

[3] FAO, World inventory of fisheries. Impact of aquaculture on environment. Issues Fact Sheets. Text by Uwe Berg., in: FAO Fish. Aquac. Dep. Online, Rome, 2005.

[4] M.B. Timmons, J.M. Ebeling, Recirculating aquaculture, 3rd edition, Ithaca Publishing Company, LLC, Ithaca, NY, 2013.

[5] S.E. Yeo, F.P. Binkowski, J.E. Morris, Aquaculture effluents and waste byproducts: Characteristics, potential recovery, and beneficial reuse, NCRAC Tech. Bull. 6 (2004).

[6] A. Graber, R. Junge, Aquaponic systems: Nutrient recycling from fish wastewater by vegetable production, Desalination. 246 (2009) 147-156. doi:10.1016/j.desal.2008.03.048.

[7] O. Pulz, W. Gross, Valuable products from biotechnology of microalgae, Appl. Microbiol. Biotechnol. 65 (2004) 635-648. doi:10.1007/s00253-004-1647$\mathrm{X}$.

[8] H. Milhazes-Cunha, A. Otero, Valorisation of aquaculture effluents with microalgae: The Integrated Multi-Trophic Aquaculture concept, Algal Res. 24 (2017) 416-424. doi:10.1016/j.algal.2016.12.011.

[9] A. Muller-Feuga, Microalgae for aquaculture: The current global situation and future trends, in: A. Richmond (Ed.), Handb. Microalgal Cult. Biotechnol. Appl. Phycol., Blackwell, Oxford, UK, 2007: pp. 352-364.

[10] M. Sørensen, Y. Gong, F. Bjarnason, G.K. Vasanth, D. Dahle, M. Huntley, V. Kiron, Nannochloropsis oceania-derived defatted meal as an alternative to 
fishmeal in Atlantic salmon feeds, PLOS ONE. 12 (2017) e0179907. doi:10.1371/journal.pone.0179907.

[11] J. Benemann, Microalgae for biofuels and animal feeds, Energies. 6 (2013) 5869-5886. doi:10.3390/en6115869.

[12] J. de la Noüe, G. Laliberté, D. Proulx, Algae and waste water, J. Appl. Phycol. 4 (1992) 247-254. doi: 10.1007/BF02161210.

[13] J.R. Benemann, D.M. Tillett, Utilization of carbon dioxide from fossil fuelburning power plants with biological systems, Energy Convers. Manag. 34 (1993) 999-1004. doi:10.1016/0196-8904(93)90047-E.

[14] A.M. Lizzul, P. Hellier, S. Purton, F. Baganz, N. Ladommatos, L. Campos, Combined remediation and lipid production using Chlorella sorokiniana grown on wastewater and exhaust gases, Bioresour. Technol. 151 (2014) 12-18. doi:10.1016/j.biortech.2013.10.040.

[15] Z. Guo, Y. Liu, H. Guo, S. Yan, J. Mu, Microalgae cultivation using an aquaculture wastewater as growth medium for biomass and biofuel production, J. Environ. Sci. China. 25 Suppl 1 (2013) S85-88. doi:10.1016/S1001-0742(14)60632-X.

[16] T. Halfhide, A. Åkerstrøm, O.I. Lekang, H.R. Gislerød, S.J. Ergas, Production of algal biomass, chlorophyll, starch and lipids using aquaculture wastewater under axenic and non-axenic conditions, Algal Res. 6, Part B (2014) 152159. doi:10.1016/j.algal.2014.10.009.

[17] V. Andreotti, A. Chindris, G. Brundu, D. Vallainc, M. Francavilla, J. García, Bioremediation of aquaculture wastewater from Mugil cephalus (Linnaeus, 1758) with different microalgae species, Chem. Ecol. 33 (2017) 750-761. doi:10.1080/02757540.2017.1378351.

[18] J. Peccia, B. Haznedaroglu, J. Gutierrez, J.B. Zimmerman, Nitrogen supply is an important driver of sustainable microalgae biofuel production, Trends Biotechnol. 31 (2013) 134-138. doi:10.1016/j.tibtech.2013.01.010.

[19] M.H.A. Michels, M. Vaskoska, M.H. Vermue, R.H. Wijffels, Growth of Tetraselmis suecica in a tubular photobioreactor on wastewater from a fish farm, Water Res. 65 (2014) 290-296. doi:10.1016/j.watres.2014.07.017.

[20] F. Gao, C. Li, Z.-H. Yang, G.-M. Zeng, L.-J. Feng, J. Liu, M. Liu, H. Cai, Continuous microalgae cultivation in aquaculture wastewater by a membrane photobioreactor for biomass production and nutrients removal, Ecol. Eng. 92 (2016) 55-61. doi:10.1016/j.ecoleng.2016.03.046.

[21] C.-M. Kuo, J.-F. Jian, T.-H. Lin, Y.-B. Chang, X.-H. Wan, J.-T. Lai, J.-S. Chang, C.-S. Lin, Simultaneous microalgal biomass production and $\mathrm{CO}_{2}$ fixation by cultivating Chlorella sp. GD with aquaculture wastewater and boiler flue gas, Bioresour. Technol. 221 (2016) 241-250. doi:10.1016/j.biortech.2016.09.014.

[22] N. Zou, C. Zhang, Z. Cohen, A. Richmond, Production of cell mass and eicosapentaenoic acid (EPA) in ultrahigh cell density cultures of Nannochloropsis sp. (Eustigmatophyceae), Eur. J. Phycol. 35 (2000) 127133. doi:10.1080/09670260010001735711.

[23] J. Doucha, K. Lívanský, Productivity, $\mathrm{CO}_{2} / \mathrm{O}_{2}$ exchange and hydraulics in outdoor open high density microalgal (Chlorella sp.) photobioreactors operated in a Middle and Southern European climate, J. Appl. Phycol. 18 (2006) 811-826. doi:10.1007/s10811-006-9100-4. 
[24] J. Doucha, K. Lívanský, High density outdoor algae culture technology, in: R.K. Baipai, A. Prokop, M. Zappi (Eds.), Algal Biorefineries, Springer, 2013: pp. 147-173.

[25] I. Brányiková, B. Maršálková, J. Doucha, T. Brányik, K. Bišová, V. Zachleder, M. Vítová, Microalgae - novel highly efficient starch producers, Biotechnol. Bioeng. 108 (2011) 766-776. doi:10.1002/bit.23016.

[26] J.A. González, J. Calbó, Modelled and measured ratio of PAR to global radiation under cloudless skies, Agric. For. Meteorol. 110 (2002) 319-325. doi:10.1016/S0168-1923(01)00291-X.

[27] R Development Core Team, R: A language and environment for statistical computing, Vienna, Austria, 2010. http://www.R-project.org.

[28] L. Granada, N. Sousa, S. Lopes, M.F.L. Lemos, Is integrated multitrophic aquaculture the solution to the sectors' major challenges? - a review, Rev. Aquac. 8 (2016) 283-300. doi:10.1111/raq.12093.

[29] A. Lee, D. Lewis, T. Kalaitzidis, P. Ashman, Technical issues in the large-scale hydrothermal liquefaction of microalgal biomass to biocrude, Curr. Opin. Biotechnol. 38 (2016) 85-89. doi:10.1016/j.copbio.2016.01.004.

[30] A. Endut, A. Jusoh, N. Ali, W.B. Wan Nik, A. Hassan, A study on the optimal hydraulic loading rate and plant ratios in recirculation aquaponic system, Bioresour. Technol. 101 (2010) 1511-1517. doi:10.1016/j.biortech.2009.09.040.

[31] J. Colt, G. Tchobanoglous, Evaluation of the short-term toxicity of nitrogenous compounds to channel catfish, Ictalurus punctatus, Aquaculture. 8 (1976) 209-224. doi:10.1016/0044-8486(76)90084-3.

[32] A. Wäckerlin, Mikroalgen-Mischkulturen - Anwendung eines ökologischen Prinzips, Bachelor thesis, Zurich University of Applied Sciences, 2013.

[33] V. Montemezzani, I.C. Duggan, I.D. Hogg, R.J. Craggs, A review of potential methods for zooplankton control in wastewater treatment High Rate Algal Ponds and algal production raceways, Algal Res. 11 (2015) 211-226. doi:10.1016/j.algal.2015.06.024. 


\section{Supplemental figures}
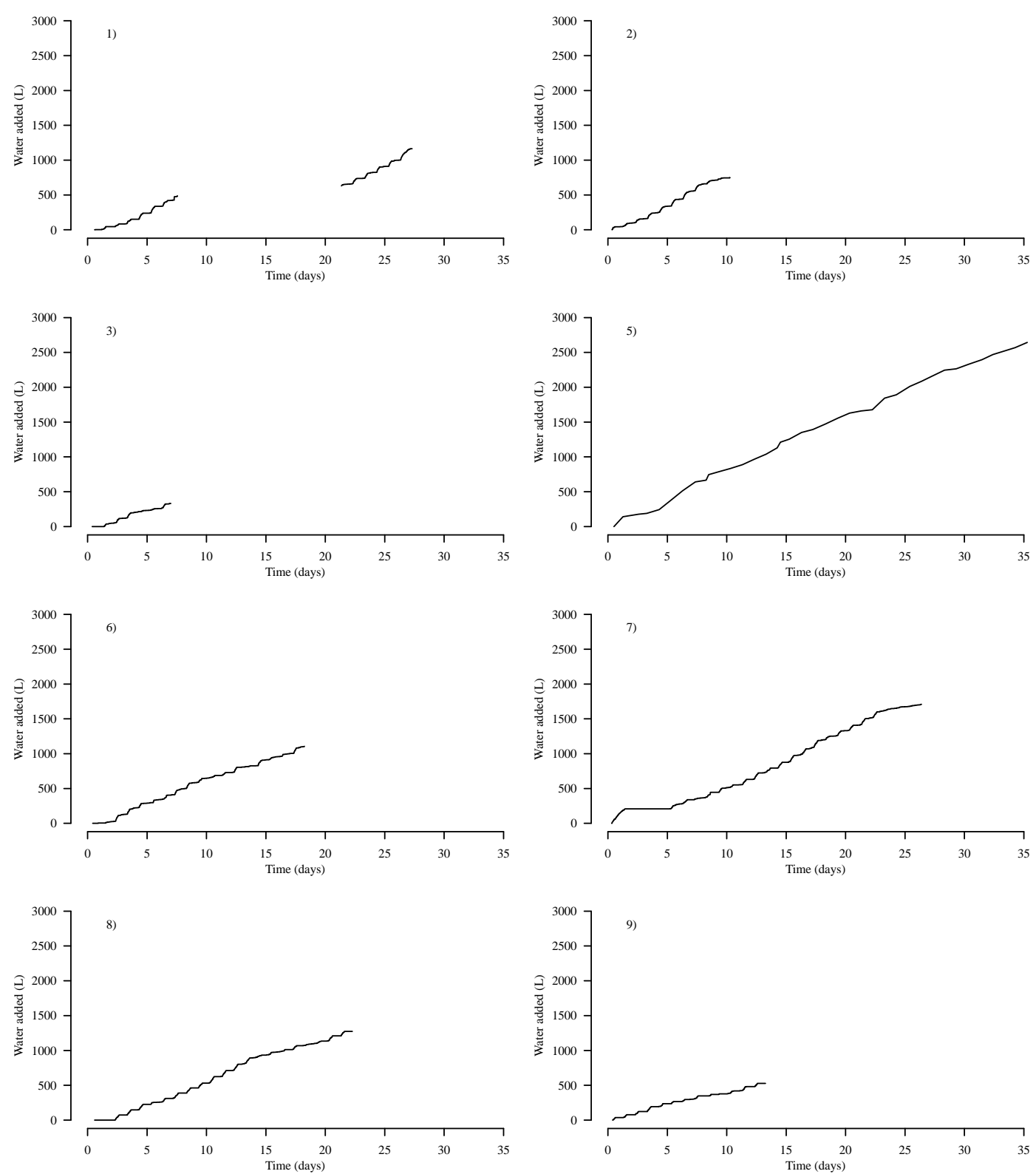

Figure S1: Water added to cultures to balance loss by evaporation. Numbers correspond to Table 1. Sensor malfunction caused a data gap in cultivation 1 , after which the water meter resumed counting. Seven days into cultivation 3 , the water meter broke and was not available for the rest of the cultivation and during cultivation 4 . 

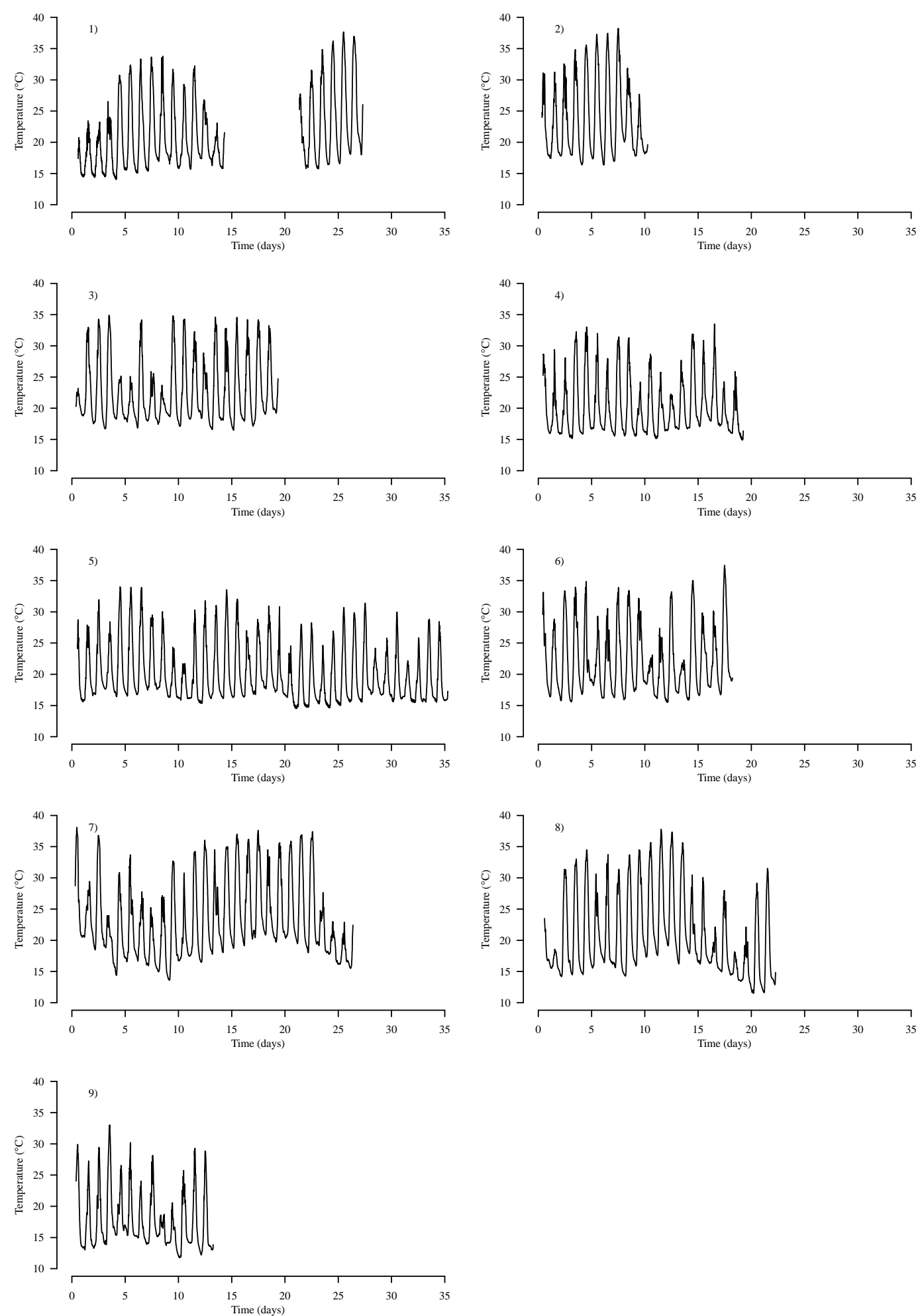

Figure S2: Temperature profiles of all nine cultivations as listed in Table 1. 

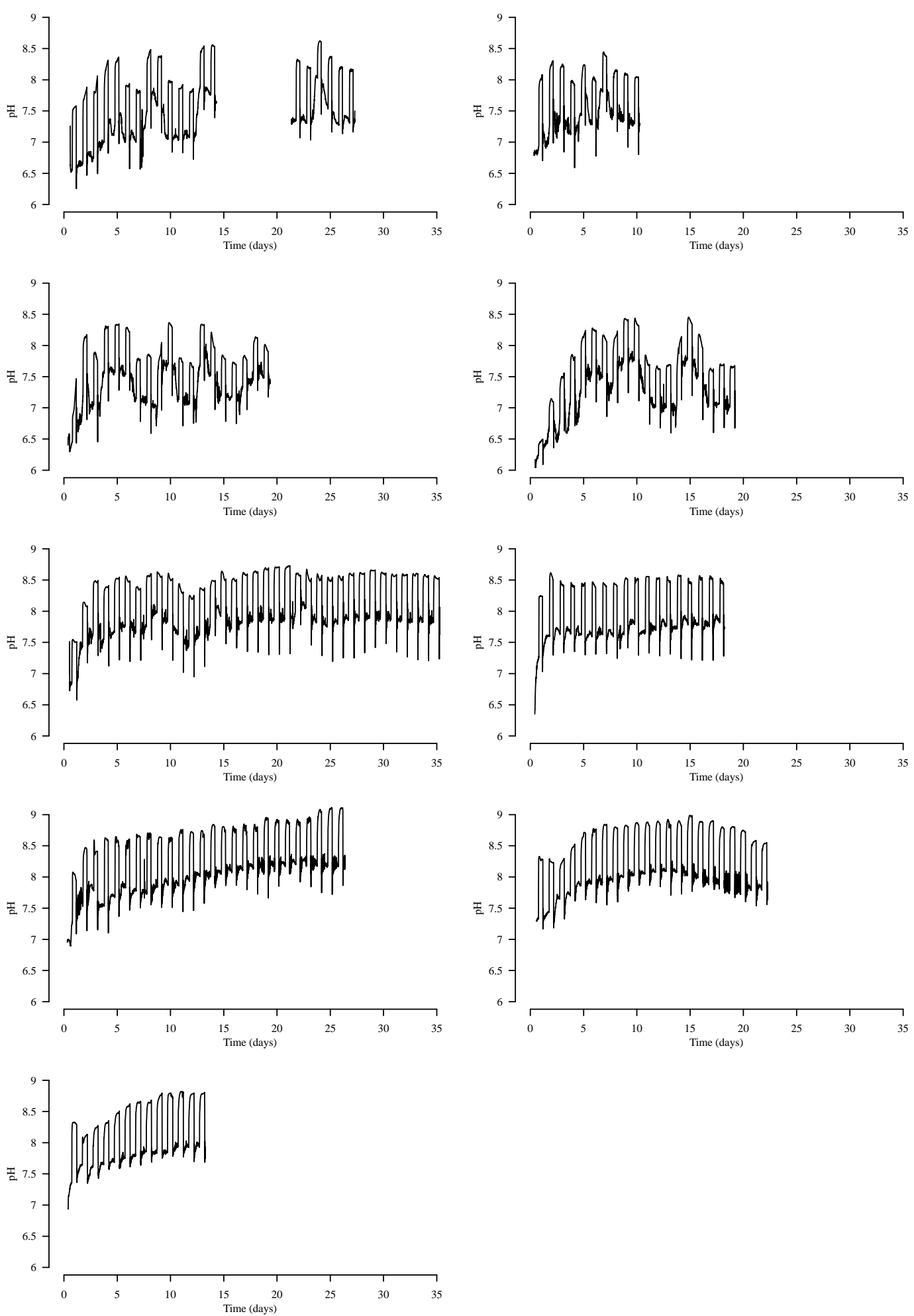

Figure S3: pH profiles of all nine cultivations as listed in Table 1. The daily pattern is explained by the addition of $\mathrm{CO} 2$ during daytime, which causes a shift in $\mathrm{pH}$. 